\title{
Lenz, Latorre y el archivo popular de la nación
}

\author{
Pablo Concha Ferreccio ${ }^{1}$ \\ Universidad de Chile, Chile
}

\begin{abstract}
Resumen
En este ensayo exploro la cercana relación entre filología y criollismo en Chile. Propongo comprender este intercambio productivo desde la idea de archivo popular de la nación, cuyo objeto privilegiado serían las manifestaciones culturales populares. Este dispositivo hermenéutico habría sido iniciado por el filólogo y folclorista alemán Rodolfo Lenz y continuado luego por folcloristas y autores literarios entre los que destaca el principal exponente del criollismo, Mariano Latorre. Discuto los problemas de lectura asociados a los dos objetos que privilegió este archivo: la lengua o dialecto vulgar y el folclor, considerando los lugares diferenciales de enunciación de Lenz y de Latorre.
\end{abstract}

Palabras clave: Rodolfo Lenz, Mariano Latorre, criollismo, folclor, cultura popular, hispanismo.

LENZ, LATORRE AND THE POPULAR ARCHIVE OF THE NATION

Abstract

This article examines the close relation between philology and criollismo in Chile. I propose to comprehend this productive interchange from the idea of a popular archive of the nation, which

1 Para correspondencia, dirigirse a: Pablo Concha Ferreccio (pabloconchas@gmail.com). 
privilege object is popular culture manifestations. This hermeneutic device would have been by the German philologist and folklorist Rodolfo Lenz and then continued by folklorists and literary authors, among which the main exponent of criollismo, Mariano Latorre, stands out. I discuss the reading problems associated with the two encarnations of popular culture that this archive privileged: the vulgar language or dialect and folklore, considering the different places of enunciation of Lenz and Latorre.

Keywords: Rodolfo Lenz, Mariano Latorre, criollismo, folklore, popular culture, hispanism.

Recibido: $13 / 07 / 20 \quad$ Aceptado: $30 / 10 / 20$

\section{PROBLEMA Y PROPUESTA ${ }^{2}$}

Difícilmente se hallará hoy una corriente literaria que suscite menor interés crítico que el criollismo. Nuestra comprensión de aquella pasa por un conjunto de categorías que ya no se discuten, entre otras cosas porque su fama de predecible, monótona, paternalista, nacionalista, mimeticista, artificial, cosificante, oficialista y políticamente tibia $\mathrm{o}$, sin más, conservadora, parece dispensarnos una lectura directa de los textos. Compartimos cierto sentido común sobre lo que el criollismo fue y sobre su relevancia para la historia literaria nacional, dada por un sentido de referencia negativa, de fondo contra el cual se recortó la literatura política y técnicamente valedera: el criollismo es recordado sobre todo porque dos de nuestros principales escritores, Marta Brunet y Manuel Rojas, lo superaron a tiempo. Si muchos de estos juicios sobre el criollismo son atendibles y bien fundados, también es cierto que su revisitación crítica sería provechosa para desmenuzarlo con precisión, para leer las funciones que cumplió a nivel de campo respecto de otras corrientes literarias y a nivel de pensamiento social, político y cultural, para describir sus mecanismos de significación textual, para entender mejor su aproximación a la cultura popular, entre otros varios asuntos. Con ello

2 Este artículo se basa en mi tesis de magíster, La genealogía filológica: regionalismo literario y comunidades imaginadas en Brasil y Chile. Retomo también asuntos expuestos en Concha Ferreccio 2019. 
ganaríamos una comprensión más rica no solo del criollismo en particular, sino también de un capítulo de la historia literaria chilena en general.

En este ensayo intento aportar a la comprensión del criollismo a través de su relación con otros discursos, con los cuales informó aquella cultura nacionalista de orden mesocrático surgida hacia fines del siglo XIX y consolidada en la década de 1920. Me refiero al discurso de la filología y de los estudios folclóricos, que se aliaron a mediados del siglo XIX en Europa y que hicieron su desembarco en el Instituto Pedagógico de la Universidad de Chile en 1889 de la mano del filólogo y etnólogo alemán Rodolfo Lenz 3 . Actualmente hay un auge de estudios sobre Lenz desde distintas disciplinas (filología, lexicografía, traducción, antropología, etc.), pero su indagación orientada a la reflexión literaria ha sido más bien escasa. Quien primero se interesó en el asunto fue Juan Poblete (2003: 253), al abordar en un libro ya clásico el impacto de las reformas pedagógicas de Lenz en lo que desde 1925 sería la "nacionalización" del canon literario escolar chileno. La mirada de Poblete se enfocaba sobre todo en los quiebres de Lenz con la tradición gramatical preceptista del siglo XIX, pero además proyectaba los sentidos en que la reforma pedagógica de Lenz había alimentado procesos culturales más amplios en el siglo venidero.

Retomando esa mirada prospectiva, considero el campo literario chileno de inicios del siglo XX como una esfera en que las ideas lingüísticas y culturales de Lenz mostraron un alcance amplio y que describió un curso independiente respecto de los planteamientos del filólogo y del devenir de su pensamiento. El impacto que supuso la entrada de la "lengua huasa", vía Lenz, en el arte literario de inicios de siglo fue evaluado por Subercaseaux (2007: 17, 160-161) como una ampliación de la lengua literaria, en sintonía con la voluntad de integrar a sectores de la población antes excluidos de la comunidad nacional. De manera similar, Poblete (2003: 253) afirma que la dignificación de la palabra popular redefinió lo literario. Ambas ideas surgen a partir de la preeminencia romántica que Lenz otorgó al estudio del "dialecto vulgar" (la lengua del pueblo), visto como la expresión más pura y auténtica del espíritu nacional chileno. Ahora bien, para especificar lo anterior, diremos que lo popular encuentra dos cauces culturales distintos pero relacionados: el dialecto vulgar y el folclor ${ }^{4}$. Aquí comienzan los problemas. Aunque parezca

\footnotetext{
Para una biografía de Lenz, $c f$. Escudero 1963; para una visión de conjunto de su obra, cf. Pavez 2015.

4 Según indica Corominas, "folclor" proviene etimológicamente de folklor, "compuesto de folk 'gente, vulgo' y lore 'erudición', 'conjunto de hechos y creencias' (de la misma raíz que learn 'aprender')" (1980: 925). Algunos diccionarios no consignan dos acepciones de
} 
una obviedad, el dialecto vulgar no habita solo en el repertorio lingüístico de la sociedad y el folclor es una manifestación que se puede representar y estudiar de distintas maneras. De esto eran especialmente concientes los escritores criollistas y en general todos los allegados a la corriente literaria vernacular, que lo sometieron a diversos tratamientos estilísticos.

Carlos Alonso ha propuesto una forma de entender la relación entre novelas regionalistas (como las criollistas) y filología, al señalar que "the discipline of philology provides the essential concepts and relationships that legitimizes and control the writing of these novels" (1990: 64, énfasis en el original). Alonso (1990: 64-66, 73-76) sostiene el carácter moderno de estos textos mediante el enfrentamiento de las dos escrituras que los constituirían: una es heredada del método filológico, que intenta llevar al papel una esencia autóctona expresada en la oralidad; la otra es de carácter crítico, pues comenta sobre los problemas y, en última instancia, la imposibilidad de tal empresa. En esta autoconsciencia de los textos regionalistas, que cancela la transparencia e ingenuidad que hasta hoy se les endilga, residiría su valor productivo en cuanto textos literarios.

Ahora bien, la consideración histórica del supuesto romántico-naturalista de base que comparten filología y criollismo (existe un núcleo auténtico del ser nacional que se expresa como una visión de mundo (Weltanschauung) en las manifestaciones tradicionales del pueblo, las que entonces es necesario salvaguardar de la modernización que amenaza con destruirlas) nos permite comprender su articulación desde la noción de archivo. Para Derrida (1997), el archivo designa un conjunto de materiales de naturaleza diversa que se rige por un principio topo-nomológico: refiere a un comienzo físico (lugar) y ontológico (el origen) e, igualmente, a un mandato o ley. El archivo debe su sentido al arkheîon griego: "en primer lugar, una casa, un domicilio, una dirección, la residencia de los magistrados superiores, los arcontes, los que mandaban" (10). Estos arcontes cuentan con un poder de consignación, en virtud del cual guardan la memoria oficial, seleccionan los signos que la constituyen, los reúnen, identifican e interpretan (10-11). De esta manera,

la raíz "lore", sino dos definiciones de folclor que se toman como complementarias. Así, en el diccionario de Alemany Bolufer: "Conjunto de leyendas y tradiciones populares. Conocimiento, o estudio de las leyendas y tradiciones populares" (1917: 786); y en el de Rodríguez-Navas y Carrasco: "Conjunto, conocimiento, estudio de leyendas, tradiciones y manifestaciones del arte popular que describe, caracteriza y da sello peculiar a una región o país.-Voz inglesa; de folk, pueblo y lore, ciencia" (1918: 821). Este dato etimológico da cuenta de hasta qué punto se puede hablar de una cultura popular, pues la palabra misma ya supone el conocimiento de lo que intenta designar: el objeto y el saber sobre ese objeto se encuentran imbricados en ella. 
el archivo es un dispositivo de poder albergado en un soporte de inscripción exterior a la memoria "orgánica", el que entonces asegura su pervivencia y busca estabilizar sus condiciones de legibilidad ${ }^{5}$. Sin embargo, esta misma exterioridad es la condición de su potencial ruina, pues en tanto asegura su repetición y memorización, se asocia con la pulsión de muerte freudiana (19-21). Por último, cabe acotar que la dinámica de inscripción del archivo se basa en una violencia archivadora que reduce la heterogeneidad de los materiales que lo constituyen. Por esta razón, Derrida considera necesario deconstruir los criterios de constitución y de acceso al archivo; en una palabra, cuestionar sus límites (12). Los tres elementos que destacamos: (1) la relación con el origen, (2) la condición exterior y su concomitante deriva destructiva y (3) la necesidad de democratizarlo resultan clave para entender los tratamientos que folcloristas y escritores dedicaron a los materiales que componían el archivo.

Propongo hablar de un archivo popular de la nación porque entiendo que la filología, los estudios folclóricos y el criollismo colaboraron de diferentes maneras en la postulación de un origen y de un modo de lectura para la comunidad nacional que se basaba en la cultura del pueblo ${ }^{6}$. Nuestros autores pueden ser pensados como arcontes, como agentes que guardan y normalizan una lectura de lo que esas naciones supuestamente son o deberían ser. Las publicaciones de Lenz, iniciadas a finales del siglo $\mathrm{XIX}^{7}$, dieron a conocer las canciones, poesías y narraciones que se hallaban en boca del pueblo basándose en la teoría etnográfica y en un enfoque comparatista de la lengua, método que marca el nacimiento de la filología moderna (Foucault 1968). La particularidad del archivo que podemos leer desde Lenz es que postula el origen de la nación a partir de la figura etnosociológica del mestizo y de la cultura popular, representados por excelencia en la figura del roto ${ }^{8}$

5 Aclaramos que es este presupuesto -el de una memoria orgánica independiente de soporte protético alguno- el que discute Derrida. En tal sentido, antecedente obligado de Mal de Archivo es el ensayo "Freud y la escena de la escritura", contenido en La escritura y la diferencia (1989).

6 Raúl Rodríguez Freire se refiere de manera más general a un archivo terrícola al que los intelectuales y escritores apelarían para encumbrar un concepto de identidad o memoria propia y exclusiva de América Latina (2015: 83-84).

7 Las primeras publicaciones de Lenz al respecto son "Chilenische Studien [Estudios chilenos]" (1891-1892) y "Ensayos filolójicos americanos" (1894).

8 Si bien esta figura remonta su origen a la conquista y señala la mezcla de mapuche con español, es después de la Guerra del Pacífico (1879-1883) que su empleo se extenderá por la población con un marcado matiz nacionalista (Subercaseaux 2007). El roto como símbolo identitario encontrará su lugar de representación predilecto en la literatura criollista, henchida del mismo ánimo paternalista hacia el pueblo que en el siglo XIx. Este nacionalismo, dentro del 
y en el folclor. Así, filólogos, folcloristas y escritores intentan articular una comunidad cultural que reconocen híbrida, pero dentro de la cual destacan un elemento constitutivo antes desconsiderado por la historia; en este caso, el autóctono ${ }^{9}$. El principal antecedente de Lenz y su labor archivadora, en este sentido, sería Andrés Bello, quien a través de su edición del Poema del Cid buscó restablecer la filiación de los criollos con su origen europeo para reforzar su hegemonía política y cultural en Chile (Ennis 2015: 118) ${ }^{10}$. Es interesante que, en paralelo a ese trabajo, Bello también se dedicara al estudio de La Araucana, que presentaba como piedra fundante de la tradición literaria chilena. Es así que Bello inicia en Chile "la construcción de una tradición literaria prestigiosa y remota, acorde a los modelos de la Europa moderna, que vuelve a España en cuanto sitúa allí su archivo, pero traslada la autoridad del arconte -del filólogo devenido gramático-al letrado criollo" (Ennis 2015: 123). Volveré más adelante sobre cómo ambos archivos se enfrentan pero también se concilian.

Para aproximarnos al vínculo filología-criollismo también se debe destacar la función que se le reservó a la filología al interior de la ciudad letrada latinoamericana. Como ya se ha estudiado, esa disciplina desempeñó un papel fundamental en la construcción de nación durante el siglo XIX, al proveer, entre otras cosas, criterios de civilidad y de identidad lingüística tanto nacional como americana ${ }^{11}$. Más aún, producto del interés por "lo propio" y el mundo autóctono, la filología, bajo el alero del positivismo, se cruzó con los estudios folclóricos hacia finales de aquel periodo. Esto da pie para pensar que el criollismo no solo se relaciona con el proceder disciplinar o con los fundamentos epistemológicos de la filología, sino además con el carácter programático que adquiere una vez que la consideramos de manera situada, es decir, en tanto pieza clave de los procesos modernizadores locales que tuvieron al Estado-nación como horizonte de organización política. Vistos desde una óptica histórica entonces, filología y criollismo

cual ya está Lenz, mostrará sus diferencias con el republicano en el ideario y en la procedencia social de sus adherentes, que ahora vienen de unas capas medias ilustradas (Vicuña 2001: 39).

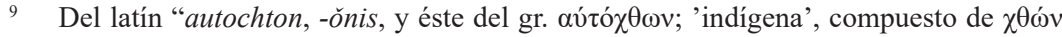

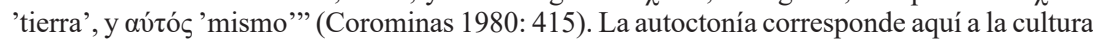
mapuche y a la cultura del pueblo chileno.

10 Bello se abocó al estudio y restauración textual del Poema del Cid desde su exilio en Londres, entre 1817 y 1829, y volvió a él durante toda su vida, sin jamás darle término (Ennis 2015: 106-107). El Ministerio de Instrucción Pública de Chile lo publicó recién en 1881.

11 Esto es lo que propone, por ejemplo, Julio Ramos en torno al pensamiento de Andrés Bello sobre la relación entre lengua y Estado nacional, en Desencuentros de la modernidad en América Latina, pp. 35-49. 
pueden no solo polemizar, sino también establecer lazos de complicidad, de negociación. Enfocar esta zona gris en que una y otro se yuxtaponen parcialmente implica relevar no solo discursos, sino también prácticas, redes y circuitos intelectuales y culturales. De ahí la pertinencia de incorporar a nuestro planteamiento una perspectiva glotopolítica, que complementa lo que puede hacerse desde la historia de la cultura, de la literatura y el análisis literario.

Por ocuparse del nudo lenguaje-política tal como se desenvuelve en sociedad (Del Valle 2017: 17), el enfoque glotopolítico ${ }^{12}$ provee un nivel de especificidad analítica sobre lo lingüístico que enriquece el aporte de las escuelas desde las que suele pensarse la literatura (estructuralismo, posestructuralismo, deconstrucción, semiótica, marxismo). Si tomamos a la glotopolítica como una perspectiva relevante para la dilucidación del fenómeno literario, podemos volver a pensar las dinámicas lingüísticoideológicas de los textos en relación con discursos y prácticas del campo cultural que atañen al lenguaje pero que no siempre son considerados por los estudios literarios (me refiero al papel del lenguaje, por ejemplo, en las (auto) representaciones de agentes sociales, en el prestigio de corrientes literarias, o en relación con el diseño e implementación de políticas lingüísticas, la circulación y el debate sobre ideologías lingüísticas o las representaciones del cambio lingüístico, entre otros). Es lógico que la discusión sobre el vínculo entre lengua y política se haya explotado ante todo en el siglo XIX, por las razones mencionadas en el párrafo anterior. Esta discusión ha merecido menor atención crítica en el siglo XX debido a la autonomía que alcanza lo literario hacia 1920 (Catalán 1985: 138-139) ${ }^{13}$; sin embargo, es pertinente traerla a colación a propósito del criollismo, estética que, entre otras cosas, busca autorizarse públicamente mediante la integración de una variedad lingüística desconsiderada por la tradición literaria decimonónica. La glotopolítica puede ayudar a iluminar la tensión entre autonomía y heteronomía que caracterizó al criollismo.

Quien abrazó con mayor entusiasmo el proyecto de Lenz fue Mariano Latorre, considerado el principal exponente del criollismo. Latorre fue

12 Para Del Valle, la perspectiva glotopolítica corresponde al "ejercicio de un análisis que revele el modo en que la variación, las estructuras discursivas o las ideas sobre el lenguaje cobran sentido en un contexto definido por diversas temporalidades - desde la situación inmediata hasta su continuidad con procesos de más larga duración- y por las condiciones de producción y reproducción de la desigualdad" (2017: 18-19).

13 Una importante excepción es un reciente número monográfico sobre crítica cultural y glotopolítica publicado en la revista española Theory Now, coordinado por Jorge Locane (2019). 
alumno de Lenz en el Instituto Pedagógico, adonde llegaría a hacer clases de Castellano en 1929. En su Autobiografía de una vocación (1953) el escritor criollista revela su profunda admiración por el filólogo alemán, a quien ya había dedicado una semblanza en 1915. Mostrando su acuerdo con Lenz, Latorre sostiene que la dilucidación de la condición histórico-literaria de América Latina encuentra su sustento en la cultura popular: "Si no se insiste en el exhaustismo de las fuentes (el folklore es el archivo general) se harán bellas generalizaciones estéticas que escamotean, a final, el problema esencial de América" ([1953]: 54, énfasis mío). Asimismo, en la década del treinta Latorre había llegado a afirmar: "La sola transcripción del testigo aficionado folklórico con escasas adiciones, es ya la interpretación del problema del campo chileno" (1971 [1936]: 284, énfasis mío). En estas palabras hay todo un proyecto y una metodología, basadas en un énfasis documentalista que atraviesa la producción de Latorre y que tiene dos vertientes discursivas: los estudios filológico-folclóricos y el naturalismo ${ }^{14}$. A pesar de su espíritu pretendidamente científico, el naturalismo presenta respecto del folclorismo una importante diferencia. Si ya en La novela experimental (1880) Zola defiende la idea de una literatura mimética, que la comprende en tanto "documento humano", al mismo tiempo fundamenta científicamente la necesidad de un temperamento, de una subjetividad, que la conduzca. Se trata de una visión paradójica, que ata un realismo de pretensiones científicas con la creencia romántica en un genio individual (Baguley 1990: 57). Latorre era bien conciente de ello, por lo que el sentido de su proyecto literario se comprenderá al considerar sus afirmaciones sobre literatura y cultura en conjunto con la literatura que él efectivamente escribió. En virtud de esa confrontación se podrá apreciar la inscripción de Latorre en el archivo popular de la nación.

Mi objetivo general aquí es estudiar las interpretaciones tensionadas que encontró la cultura popular al interior del archivo propuesto, a partir de dos de los objetos o manifestaciones que la fundan: la lengua vulgar y el folclor. Como ya he tratado el problema del folclor en Lenz (Concha Ferreccio 2019), comienzo observando las relaciones que recomendó entre dialecto vulgar y lengua literaria en el contexto de lo que él entiende como lenguaje nacional.

14 Ambos discursos estaban bastante emparentados, pues eran retoños del positivismo. Léase el prefacio de Zola a L'assomoir (La taberna): "Mi crimen consiste en haber tenido la curiosidad literaria de recoger y de vaciar en un molde muy estudiado, el lenguaje del pueblo [...] Es un bocado delicioso para los gramáticos investigadores [...] nadie ha sabido ver que mi deseo era hacer un trabajo puramente filológico, que considero de vivo interés histórico y social" (s/f [1877]: V). 
Desde aquí podemos observar cómo Lenz leyó la literatura de tendencia nacionalista, comentario que sirve de puente para pasar a la perspectiva de Latorre. En el segundo acápite reviso la significación que tuvieron la figura y el pensamiento de Lenz en el proyecto literario de Latorre y la forma en que este consideró la relación entre variedades lingüísticas. En tercer lugar, analizo cómo la literatura de Latorre se hace cargo de estos problemas desde el punto de vista de la enunciación textual y de la representación de lo popular. Concluyo ponderando los hallazgos en el marco del archivo popular de la nación y de la literatura criollista. La tesis general es que este archivo, aunque fundado en una idea de cultura popular chilena, también incorporó al discurso hispanista. Tal ideología no alcanzó a amenazar el protagonismo de lo autóctono o a desplazarlo, pero impactó en su comprensión, ya fuera por el tutelaje reconocido a la cultura española o por la inferioridad atribuida a la cultura chilena. De aquí se deriva también la necesidad de reenfocar la literatura de Latorre: su fuerte hispanismo no solo precisa su inscripción en el archivo, sino que devela una cualidad de su proyecto literario (solo suyo) antes desconsiderada.

\section{LENZ LEE LA CULTURA POPULAR CHILENA}

Ya hacia mediados del siglo XIX, el filólogo se había convertido en el intérprete privilegiado de la vida secreta o del espíritu de la comunidad nacional. En una conferencia leída en la Universidad de Basilea en 1869, el joven filólogo Friedrich Nietzsche destacó que uno de los logros de la disciplina había sido "el descubrimiento y dignificación del «alma popular»" (Homero y la filología clásica 34), la pretensión de reconstruir un pasado perdido en base a los textos o a la literatura popular de un ente colectivo. Entendidas como ciencias anticuarias o arqueológicas, la filología y los estudios folclóricos, sin embargo, soslayaron la dimensión histórica de las civilizaciones que quisieron exhumar, y mediante sus mecanismos de laboratorio -como los llamó Said ${ }^{15}$ - intentaron darse las condiciones de

15 En su clásico Orientalismo (1979), y a partir del análisis de la obra de Ernest Renan, Edward Said sostiene que la nueva filología debe entenderse como una ciencia moral, guiada por demostraciones científicas puramente abstractas, que habilitó el nacimiento de la teoría racial, la opresión económica y el etnocentrismo. Así, los conceptos de raza, mente, cultura y nación se convierten en "formulaciones de invernadero" que justifican la dominación de Occidente sobre Oriente o que, más bien, lo inventan (203-204). 
su legimitidad ${ }^{16}$. Michel de Certeau afirmó que el folclor -y la filología, agregamos nosotros- efectúa una asimilación cultural que museifica y normaliza, mediante la tipificación, la cultura popular. El supuesto del origen perdido, del que arranca el rescate de lo propio, está en la misma base de la práctica investigativa de los estudiosos. La concepción de lo popular como lo verdadero, lo natural, lo espontáneo, no hace sino esconder al oficio su premisa fundante (De Certeau 54). Las palabras que dedicara al nacimiento de los estudios foclóricos franceses también son aplicables al contexto aquí tratado, aunque la amenaza que se intentaba exorcizar era allí la de la cultura oriental. En palabras del francés:

Estos estudios sobre la cultura popular se dan por objeto su propio origen. Persiguen en la superficie de los textos, delante de sí, lo que en realidad es su condición de posibilidad: la eliminación de una amenaza popular. No es sino suprimiendo este objeto de interés que toma la figura de un origen perdido: la ficción de una realidad que debe encontrarse guarda el trazo de la acción política que la organizó. La literatura científica hace funcionar como una representación mítica el gesto que está en su nacimiento (59).

Las investigaciones de Rodolfo Lenz se inscriben en esta episteme. Lenz estuvo guiado por una preocupación "patriótica", es decir, por el convencimiento de que todo avance en materia educativa e investigativa debía contribuir al conocimiento y desarrollo del "alma nacional" chilena. En este sentido, su labor como pedagogo y folclorista debe entenderse en el marco de una modernización general que se pretendió durante la época del republicanismo laico y cientificista de finales del siglo XIX. Referente privilegiado de esta orientación es la fundación del Instituto Pedagógico, bajo el auspicio del mayor exponente del positivismo ortodoxo en materia educativa, Valentín Letelier (Hale 2000: 16). En sus estudios sobre la poesía popular chilena y la literatura oral mapuche, Lenz renovó la idea de lo nacional desde la comprensión de la lengua como el vehículo privilegiado para auscultar la psicología del pueblo.

Desde muy temprano defendió la tesis de que la raza chilena era superior a las del resto del continente debido a que el proceso de mezcla racial entre españoles y araucanos había sido más acabado en Chile, producto de lo cual

\footnotetext{
16 Según Rodríguez Adrados (1970: 87, 94-95), el frío cientificismo al que llegó la filología de la época fue una de las principales razones por las que Nietzsche se alejó de ella. El punto de quiebre comienza con la publicación de El origen de la tragedia, que fue atacada por Ulrich von Wilamowitz, uno de los filólogos más importantes de la época.
} 
el indígena resultó "absorbido i asimilado casi por completo" (1894: 131). La eugenesia atribuida a la raza es patente: "El desarrollo de la nacionalidad chilena de nuestros días ha sido paulatino i parejo i, de consiguiente, sano" (1919 [1895]: 518-519). A su vez, este proceso de homogenización racial era concomitante al de homogenización lingüística, con lo cual se podía hablar de una nación unitaria; en Chile se observaba "una nacionalidad con una lengua" (1979 [1910]: 42). Ahora bien, esta no era la lengua literaria ni la empleada por la "gente cultivada", sino la que los hombres de letras puristas y preceptistas llamaban "la jerigonza corrompida de la plebe" (1894: 123). Es de notar que la cultura mapuche se subsume entonces a la cultura que Lenz llama "criolla", y que ubica en un estrato superior dentro de la jerarquía étnica.

De ahí que la literatura que más interesa a Lenz se ubique en los extramuros de la institución literaria occidental y moderna (tal como fue definida por Pierre Bourdieu). Se trata de la literatura mapuche y de la literatura popular chilena, que realmente entiende como folclor, como materia prima sobre la cual construir una antropología del pueblo. Esta literatura poco tiene que ver con la literatura clásica de la tradición occidental cuyo estudio el mismo Lenz asume como parte de la educación formal. Prueba de ello es que el cultivo de cada una debiera permanecer -así lo propone Lenz- en esferas de desempeño lingüístico separadas, independientes, autónomas una de la otra. Mientras el cultivo de la literatura popular se hace en "dialecto vulgar", la literatura occidental y culta, que Lenz llama "lenguaje literario", se inscribe en la lengua literaria (el actual estándar) que hablan las clases medias y altas de la sociedad y cuyo mejor referente es la prensa. Ahora bien, la relación entre ambas variedades no es enteramente clara. En muchos textos Lenz oscila entre un contacto enriquecedor y una separación tajante y prudente. Por ejemplo, en su Memoria sobre las tendencias de la enseñanza del idioma patrio en Chile (1899a):

El lenguaje del bajo pueblo, el dialecto, es la principal fuente de la cual se debe enriquecer el tesoro del idioma [...] Ojalá que al fin los hispanoamericanos tuvieran suficiente respeto con su propia nacionalidad para desistir de esa devoción a una autoridad en materia lingüística [...] Se necesitaría otra Guerra del Pacífico para que se volviera a levantar estatuas del roto chileno como incorporación de la fuerza y del valor del pueblo (1899a: 17).

Este encendido llamado a la dignificación del dialecto vulgar, el único realmente nacional, cuenta sin embargo con una atenuante nota al pie:

No se crea que se trate de hacer desaparecer el límite entre lenguaje literario i el dialecto vulgar. Mui al contrario. No se contradice apreciar 
una tonada que espresa tiernos sentimientos con las sencillas palabras del bajo pueblo i luchar por la propagacion de la lengua literaria i de la enseñanza obligatoria entre esas mismas clases desheredadas (1899a: 17).

Es cierto que no hay contradicción en enseñar el uso de dos variedades lingüísticas distintas para que los alumnos provenientes de las capas populares, vía ilustración, puedan mejorar su condición social. Ahora bien, en el mismo texto Lenz ha afirmado además que el objetivo de la enseñanza es que el alumno aprecie "el lenguaje literario, tal como se usa entre la jente educada de su patria, como la espresion más lejitima para los pensamientos del pueblo chileno" (1899a: 15). La contradicción con la primera cita es solo aparente. Aquí conviene separar niveles de argumentación: uno se refiere a la relación entre la variedad peninsular y la chilena; otra, a la lengua literaria y al dialecto vulgar. La última cita está escrita luego de haber atacado los vicios de la enseñanza del castellano, que son la abstracción formulaica para enseñar gramática y literatura, así como la "falsa apreciacion de las bellezas del lenguaje literario i del valor objetivo de los autores de épocas lejanas" (1899a: 15). Es decir, se trata de una lucha por desterrar los modelos que pretenden que el estándar chileno se guíe por la norma española, incluso en la pronunciación ${ }^{17}$. Las citas extensas citadas en párrafos aparte, en cambio, están en el contexto de la discusión por la relación entre las variedades locales. Es deseable, dice Lenz, que se fomente el cultivo de las formas vulgares pero no para levantarlas como modelo nacional, sino para que alimenten la capa lingüística superior, que es el estándar de la gente instruida. En este sentido también debe entenderse la carta a Julio Saavedra Molina: "Yo creo que no es nunca el pueblo el que corrompe la lengua, aunque introduzca vocablos vulgares para enriquecer el vocabulario académico (lo mismo hizo Víctor Hugo en Francia). Cambios que entran desde abajo, son siempre conformes al jenio de la lengua" (1919 [1918]: 123).

Como lo he expuesto en otro trabajo (Concha Ferreccio 2019), Lenz entiende el lenguaje nacional como una zona de negociación entre el lenguaje vulgar, la lengua literaria y el contacto de esta última con otras variedades de castellano, sobre todo la peninsular. Lenz explica que, dada la carencia congénita de la cultura chilena (que se explica por el hecho de

17 Lenz era estratégico en su empleo de la hipérbole. En carta del 28 de julio de 1901 a Rufino José Cuervo, le explica el sentido de la Memoria, saeta contra los profesores puristas: "Es un grito de combate con motivo de la última reforma de los programas de instrucción secundaria [...] Si exajero en algunos puntos, es para conseguir algo" (citado en Schütz 1976: 551). El reconocimiento sobre la exageración respecto del uso de la variedad popular sintoniza con la nota a pie recién comentada. 
no haber desarrollado una cultura de manera "natural", esto es, con base en las manifestaciones del pueblo, como las naciones europeas), desde Chile debe "asimilarse la cultura mundial moderna" (1918: 246), expresada ejemplarmente en las literaturas francesa, alemana e inglesa. Ahora bien, si esto es lo que puede llegar a proponerse como un aporte de Lenz a partir de una distancia crítica, lo cierto es que en los textos también hay una tendencia a separar ambos dominios, y a entender el cultivo de la literatura moderna como independiente, como lo más granado dentro de la lengua literaria. La persistencia de la contradicción en su obra bien puede explicarse por el hecho de que la reflexión literaria no es su foco de interés, pues esa lengua no es más que un producto "artificial"; así, queda fuera de su jurisdicción. Lo interesante al respecto es que Lenz no polemiza en la discusión sobre la historia literaria y su enseñanza; más bien se pliega al camino tradicional. Así, por ejemplo, cuando considera la enseñanza de los últimos tres años de humanidades, que deben "formar la cultura literaria de los alumnos" (1899b: 12), remite sobre todo al Manual de composición literaria (1887 [1871]) de Barros Arana y a Elementos de la lengua castellana (1892 [1885]) de Fanor Velasco (Lenz 1899b: 45 y ss.), con especial presencia de la literatura española. Lenz (1918: 246) afirma que, por el vínculo genético de la cultura chilena con la española, se debe dar preeminencia al estudio de la cultura española en el contexto de la educación cívica de los alumnos, así como en la educación literaria se debe conceder preferencia a los autores españoles involucrados en la historia de Chile, como por ejemplo Ercilla. Es decir, Lenz no solo no interviene en el terreno de la enseñanza literaria clásica, sino que además refrenda el lugar hegemónico de España en el contacto de la cultura chilena con el mundo occidental. Esta valoración cultural se puede encontrar también en otros folcloristas ${ }^{18}$ y recibe una lectura diferente en la representación de lo popular que hace Latorre. Volveré sobre este último punto en las secciones siguientes.

Lo que más llamó la atención entre los escritores y profesores de su tiempo fue la reivindicación que hacía Lenz del lenguaje vulgar, sobre todo por la ruptura que significaba con una idea de gramática basada en la corrección lingüística, el "buen decir", y por la promoción que dio a su cultivo estético y a su estudio. El problema de la relación entre lenguaje vulgar y lengua literaria es retomado de manera singular en un texto tardío. En "Dialectología hispanoamericana", discurso que leyó al ser elegido como sugerido. 
Miembro Académico de la Facultad de Filosofía y Ciencias de la Educación de la Universidad de Chile en 1933, Lenz pasa exhaustiva revista por las publicaciones que hasta esa fecha contienen o están escritas en algún dialecto vulgar del territorio nacional. Este texto es interesante porque permite ver no solo el conocimiento que tenía Lenz sobre la literatura criollista y de tendencia nacionalista, sino que además su grado de conciencia respecto de la labor y el lugar que a él mismo le cabía dentro de esa tradición. Cual profesor, Lenz va juzgando la fidelidad de la escritura de cada texto al habla chilena (se permite incluso corregirla) y si el traspaso está marcado o no con cursivas. Comenta si las obras incluyen glosario o anexos que expliquen los términos y frases populares, y también las juzga. Así, comenta sobre el vocabulario que incluye la novela La academia político-literaria (1890) de Daniel Barros Grez: "Las 59 páginas de este apéndice contienen muchas palabras y frases interesantes. Sólo las explicaciones del origen de las voces son a menudo ridículas. El autor no tiene idea de lo que se llama etimología y filología" (62). Escrito hacia el final de su vida, "Dialectología hispanoamericana" es además un llamado a la necesaria continuación de sus esfuerzos por cartografiar el habla popular chilena y a elaborar un diccionario al respecto. Debido a su mal estado de salud, Lenz confía en que "alguno de mis antiguos alumnos del Instituto Pedagógico" (1933: 32) realice tal proyecto. Entre esos alumnos, de hecho, están dos de los autores nacionalistas que más valora Lenz: Antonio Orrego Barros y Mariano Latorre.

En la clásica antología de literatura chilena Selva lírica (Molina Núñez y Araya 1917), Orrego Barros es presentado como el primer poeta culto en emplear el habla campesina. Su poemario Alma criolla (1903) supuso un quiebre con sus anteriores poesías, que entre 1900 y 1901 publicó en Luz y Sombra (posteriormente, Instantáneas), revista dirigida por Augusto D'Halmar. Su presentación en Selva lírica destaca el influjo que sobre él tuvieron las clases de Lenz, quien lo habría estimulado en el estudio del folclor chileno a tal punto que, a pesar de provenir de la élite,

ha logrado escribir como lo habría hecho un poeta espontáneo surgido del seno del Pueblo. Nuestro escritor se interesó vivamente por las teorías y orientaciones folkloristas del Dr. Lenz e imaginó que la labor del artista debe reflejar los caracteres y tendencias que, en los órdenes étnico, demográfico, tradicionalista e histórico, constituyen la idiosincrasia de su propio país. A su juicio debe escribirse en el idioma del pueblo que, por cierto, no es el de la alta sociedad ni el científico de una época sino una lengua más propia de la raza y más fácilmente comprendida por todos (Molina Núñez y Araya 1917: 355). 
En 1903, escribe Lenz, Orrego Barros "comenzó a publicar una colección de verdaderas poesías" (49) con su Alma criolla. Inmediatamente copia una de sus leyendas populares (¡de más de cuatro páginas!), que lleva una dedicatoria al propio Lenz, "en recuerdo de su enseñanza" (Orrego Barros, cit. en Lenz 1933: 50) ${ }^{19}$. Orrego Barros también es mencionado por Lenz en su "Anexo segundo al Diccionario Etimolójico de Voces Chilenas derivadas de lenguas indígenas americanas", en que refuta la crítica que Manuel Antonio Román hiciera a la primera entrega del diccionario en cuestión ${ }^{20}$. Aquí son relevantes tanto los argumentos lingüísticos como los literarios:

he enseñado a algunos jóvenes chilenos que no necesitan avergonzarse de su lenguaje vulgar, que el cultivo poético del dialecto patrio es un título de gloria entre las naciones mas adelantadas del mundo. Fué una gran satisfaccion para mí que poetas de talento como el jóven Antonio Orrego Barros, para solo nombrar al primero, me dedicaran sus primeras poesías escritas en lenguaje vulgar chileno. Pero nunca he fomentado entre mis alumnos la tendencia de mezclar el lenguaje vulgar con la lengua literaria castellana, aunque estoi léjos de recomendar el supuesto "casticismo académico" por el cual aboga el señor Román. Creo no hacer mal servicio a Chile si continúo, en la Sociedad de Folklore chileno recien fundada por mí, enseñando a los chilenos el estudio del alma popular chilena en todas sus manifestaciones (Lenz s/f: 4-5, nota 11).

A propósito de su labor pedagógica guiada por un rescate de lo vulgar, Lenz vincula en este fragmento tres esferas de repercusión de su obra: el aula universitaria, la creación literaria y la sociedad ilustrada en general. $\mathrm{El}$ argumento, sin embargo, parece nuevamente zigzaguear en lo tocante

19 La dedicatoria fue eliminada en la reproducción de este texto que se hizo en el libro $E l$ español de Chile, editado por el Instituto de Filología de la Universidad de Buenos Aires. La cercanía entre Orrego Barros y Lenz se observa también en el viaje que hicieron juntos a la Araucanía en misión etnográfico-filológica, seguramente en 1897 (cf. Escudero 1963: 457). Orrego Barros, junto al antropólogo y crítico literario Ricardo Latcham y los folcloristas Ramón Laval y Julio Vicuña Cifuentes, serían algunos de los fundadores de la Sociedad de Folklore Chileno en 1909, empresa impulsada por Lenz. La sociedad pasó a integrar en 1913 la Sociedad Chilena de Historia y Geografía, con el nombre de Sección Folklore, y funcionó hasta 1921; luego, se reactivaría recién en 1982 (Dannemann 2010: 58-59). Asimismo es de interés el hecho de que en 1919 Orrego Barros aportara la letra para el "Himno a la flor nacional de Chile", un canto nacional a los araucanos cuya música estuvo a cargo del alemán Juan Oberstetter. En la ejecución de la pieza participaron también la esposa e hija del ministro plenipotenciario de Alemania en Chile, Friedrich von Erckert (Zig-Zag 771 (29 noviembre 1919): s.p.), lo que da cuenta del estrecho vínculo entre el poeta y la colonia alemana en Chile.

20 Para los avatares de este anexo, $c f$. Ferreccio 1979: 22; para un análisis glotopolítico de la crítica de Román y la respuesta de Lenz, $c f$. Cáceres, Ortiz y Rojas 2020: 27-30. 
a las variedades de lengua. Al inicio se afirma que "el cultivo poético del dialecto patrio" es índice de modernidad cultural y, por tanto, deseable; pero de inmediato se rechaza la mezcla entre lo alto (lengua literaria) y lo bajo (lenguaje vulgar). Al distanciarse simultáneamente de la posición conservadora de Román, que solo reconoce la variedad de prestigio como digna de cultivo, Lenz le reconoce un lugar al "dialecto patrio", siempre que este se mantenga en su lugar, asignado de antemano según el criterio evolucionista de la lengua y de la mente nacionales.

La interpretación que parece haber dominado entre los estudiantes de Lenz es la de mantener una separación fuerte entre ambas variedades de lengua. Orrego Barros no las mezclaba en un mismo poema, sino que componía enteramente en "lengua huasa". Seguía entonces el mismo camino que Alejandro Cañas Pinochet, quien de hecho dedicaba sus Escenas de la vida agrícola en ultra-Maule (1903) al costumbrista Daniel Barros Grez. Cañas Pinochet buscaba un máximo de fidelidad respecto del habla rural y de la observación de las faenas agrícolas, con el objetivo de servir al estudio lingüístico y antropológico ${ }^{21}$. La diferencia entre Orrego Barros y Cañas Pinochet es que este último resistía cualquier adorno poético o literario en general, "porque he creido que los cuadros debian ser naturalistas, i en este concepto el autor no podia hacer otra cosa que pintar al natural i desaparecer tras la figura material i moral del guaso" (1903: VI-VII)); mientras que Orrego Barros, por el contrario, había dado curso libre a su imaginación poética.

Al cultivar poesías en lenguaje exclusivamente popular, estos autores hacían parte de una perspectiva folclorista de la literatura. Un punto que quiero enfatizar es que el criollismo ya no tendrá ese objetivo literario y transformará la observación positivista. Si Cañas se inscribe en la línea de los folcloristas (con Vicuña Cifuentes y Laval, entre otros), Orrego Barros es un poeta que quiere interpretar el alma popular asumiendo su lengua como una especie de disfraz. Ambos se preguntan por la fidelidad al folclor, al material primario que observan; de ahí su inmersión absoluta en esa lengua que les resulta ajena. Ninguno de los dos puede definirse como regionalista en el sentido fuerte del término. Retomo aquí la tesis de Friedhelm SchmidtWelle, para quien habría una "literatura regional tradicional", costumbrista, decimonónica, pintoresquista, por un lado, y un "regionalismo clásico", animado por pretensiones comprensivas de largo alcance y de decidida

21 Después de la dedicatoria hay una sección llamada “Observaciones", que consiste en anotaciones sobre la lengua del libro (fonéticas y morfosintácticas). También la fonética se imita en la escritura, pues la "narración se supone hecha por un guaso" (Cañas 1903: 1). 
voluntad alegórica, nacional, por otro (2012: 120-123). Incluso si se puede afirmar que la obra de Orrego Barros es alegórica, su estilo la aleja de este conjunto de textos, pues cancela el diálogo con la literatura extranjera. El criollismo, aun cuando se enfocará igualmente en lo propio, hará parte de las particularidades técnicas de la literatura occidental moderna. Además, introducirá un narrador que es o bien ajeno a la anécdota (omnisciente) o bien se inserta como personaje en la historia, pero ya no pretenderá hacerse pasar por el hombre popular chileno.

Curiosamente, en este discurso Lenz juzga a Latorre como "uno de los mejores autores jóvenes de novelas chilenas" (1933: 64), pero indica que en sus libros no ha encontrado mucho material lingüístico de interés para su investigación: tienen poco dialecto, aun cuando Latorre "conoce bien el habla popular" (64).

\section{EL CRIOLLISMO EN EL AULA}

La lectura de Lenz que hace Latorre ha pasado prácticamente desapercibida para la crítica; solo García (1971) ha reparado en su importancia. En su Autobiografía de una vocación (1953), Latorre vuelve una y otra vez sobre el filólogo, y en un sentido que permite afirmar que la génesis de su proyecto literario participa en buena medida de las tesis del alemán. Por lo tardía de esta referencia y por encontrarse además en un texto autobiográfico, podría sospecharse negativamente de su validez para el análisis. Es sabido que en todo ejercicio rememorativo interviene una dotación de sentido y causalidad en retrospectiva, aquello que Freud llamó Nachträglichkeit (Laplanche y Pontalis 1996: 280) ${ }^{22}$. Con todo, la atribución de significado a posteriori, la resignificación del pasado, no invalida aquel texto para fines interpretativos literarios, sobre todo si queremos abordar aquí el proyecto de Latorre. La contraparte necesaria de este ejercicio es la lectura de sus textos ensayísticos y literarios, cuya producción inicia en la primera década del siglo.

22 No puede pasarse por alto el hecho de que, producto de la alta beligerancia a que estuvo expuesto el criollismo y el mismo Latorre durante la primera mitad del siglo XX, la autobiografía del escritor exhibe un cariz apologético (aclarar y defender su proyecto estético y su aporte a la literatura nacional y dar acabada cuenta de su formación intelectual) propio de una instancia consagratoria y que parece ofrecer un cierre a su trayectoria literaria: la autobiografía que comento es su discurso de incorporación a la Facultad de Filosofía y Educación de la Universidad de Chile. 
Latorre escribe sobre Lenz por primera vez en 1915. En la aparentemente ligera semblanza publicada en Sucesos, lo diferencia de la tradición filológica anterior al presentarlo como un revolucionario que en el aula pierde la gravedad magisterial para revelar un espíritu ingenioso, "alegre y dirachero [sic]" (1915a: 45), un erudito que sin embargo "busca con deleite la espontaneidad no sujeta a reglas opresoras" (45). En paralelo, Latorre acerca a Lenz a cierta idea de identidad latina: un "sol latino" dora "el espíritu de este germano lleno de geniales adivinaciones"; Lenz tiene "una chispa de oro del claro ingenio de Lutecia. Por lo demás Lenz, según la autoridad de un amigo mío, es una ciudad francesa" (45). No se piense que el dato racial es aquí un detalle; por el contrario, Latorre lo busca obsesivamente en multitud de textos sobre intelectuales y escritores que admira. La raza, el pragmatismo, el nacionalismo y el espíritu de acción son parte de una matriz epistémica positivista desde la cual Latorre produce una galería de "prohombres", representantes de una clase media masculina, ilustrada y reformista (para una descripción de esta clase media y su vínculo con el criollismo, $c f$. Barr-Melej 2001).

Entre 1915 y 1916 el criollista publica en Sucesos otras tres semblanzas de personalidades académicas: de Luis Galdames, rector del Liceo Miguel Luis Amunátegui: "hombre práctico que había de encauzar sus ideas por un camino fructífero, inmediato, positivo", de un "nacionalismo razonado" (1915b); de Enrique Nercasseau y Morán, profesor de literatura española del Instituto Pedagógico: "castizo español americano que dice como Cervantes y piensa como Menéndez Pelayo", poeta que sueña con la España del Siglo de Oro, la España portentosa del Quijote y de la conquista de América" (1916a: 31); y de Rubén Guevara, rector del Liceo Santiago: educador ejemplar que tiene un "concepto positivo y nacionalista de la vida chilena", pero además "prócer de la patria vieja", representante de la "raza visigótica, de rubias barbas y ojos azules que, en épico elogio, inmortalizó Nicolás Palacios" (1916b: 11). La lectura de Palacios, el principal intelectual chileno que movilizó las ideas racistas de Gustave Le Bon, explica entonces aquel sol latino que Latorre proyecta sobre Lenz: Palacios (1918 [1904]) propuso que la raza chilena había resultado de la mezcla entre godos y araucanos, es decir, entre germanos que viajaron a través de los españoles hasta América y allí se unieron eugenésicamente con los mapuches; dos razas guerreras, viriles y patriarcales. Las referencias citadinas francesas -Lenz y Lutecia (actual París)-acercan a Lenz a esa raza dorada que está llamada a corregir los vicios del país y a fundar una nueva identidad nacional. No es casualidad que Francia además se ubique en la genealogía familiar de Latorre, estrategia de identificación con un yo autobiográfico que recorre su obra de punta a cabo. Desde la perspectiva racista que asume Latorre, los ojos claros y el 
pelo rubio son datos fundamentales en la determinación del carácter de un individuo; de ahí que siempre que pueda mencione estas características físicas en sus ensayos pero también en su literatura, como veremos luego ${ }^{23}$.

Latorre se matricula en el Instituto Pedagógico hacia 1904 o 1905 para estudiar Leyes, pero al morir su padre abandona la carrera para asistir a Latín (impartido por Federico Hanssen), Literatura Española (a cargo de Enrique Nercasseau y Morán) y Lingüística (materia de Lenz). Tras afirmar que de las primeras dos cátedras no sacó gran provecho para el conocimiento de Chile, escribe: "Sólo Lenz me sorprendió con su milagroso instinto de filólogo y su penetración de Chile. Daba Lenz la impresión de conocer a fondo al país, sus características étnicas (las miraba con cierto desprecio) y su lenguaje, el de los huasos de los campos y el de los rotos de las ciudades y minas" ([1953]: 45). Complementa y refuerza luego: "Reparé, sí, al lado de Lenz, en cierta cualidad psicológica que me inclinaba a ver en los mestizos $\mathrm{y}$ en su paisaje cierta novedad que era la misma adivinada por Lenz, desde el punto de vista filológico" (47). Ante todo, Lenz provee a Latorre de un punto de vista, de una subjetividad a partir de la cual comprender un mundo al que no se pertenece. Se trata de la posición del inmigrante, del hombre blanco, occidental y "moderno, modernísimo" (Latorre 1915a: 45), que se sabe ajeno a la cultura popular y étnicamente marcada, pero que sin embargo (o tal vez por esa misma razón) puede acceder a su secreto ${ }^{24}$. El elemento "zahorí" (45) que Latorre destaca en Lenz será asumido como un mandato literario: ya no solo penetrar en la psicología de los chilenos, sino además representar su lucha épica con el medio en que viven. La figura del filólogo zahorí se aviene con la del poeta romántico, el "único" capaz de acceder al alma popular y, así, "restablecer la unidad perdida entre el yo y el cosmos, una organicidad que incluiría al yo observador" (González Echevarría 1998: 157). Latorre escribe que, por los mismos años, "hombres y paisajes ya no tenían secretos para mí" ([1953]: 35).

Retomo una de las citas anteriores: entre paréntesis, Latorre escribe que Lenz veía "con cierto desprecio" las cualidades étnicas de los chilenos. Este paréntesis se amplifica en otra anécdota del Instituto Pedagógico:

23 Algo del lastre positivista que arrastraba Lenz al llegar a Chile era la clasificación de lenguas por razas. En un cuaderno de clases de 1900 se lee que, de esas teorías, "la más aceptable es la que se funda en el pelo, la cual ha distinguido dos grandes grupos, a saber: / 1) Pelo ensortijado. / 2) Pelo lacio tieso y pelo lacio ondulado" (Lenz 1890: s/p).

24 "Descubrió o redescubrió [Lenz] ocultos veneros del dialecto chileno con sus refranes y modismos y creo que nadie en América llegó a un conocimiento más hondo de la expresión autóctona que, a fin de cuentas, lleva en sus raíces y sonidos fragmentos del alma de un pueblo" (Latorre [1953]: 47). 
Recuerdo que era una tarde de invierno. Llovía y berlinas y coches de postas pasaban por la calle San Miguel, arrojando pellas de barro sucio a los vidrios de la sala. El sabio se sentía defraudado. Nos miró primero, con cierto aire malicioso y nos dijo, finalmente:

-Este país es admirable, pero tiene dos grandes defectos.

Nos apresuramos a preguntarle cuáles eran esos defectos. Conocíamos su técnica.

-Que hay mucho barro y muchos chilenos, respondió cogiendo su carpeta y desapareciendo por una puerta que daba a la Sala de Profesores" $(46)^{25}$.

La mirada de Latorre no solo se identifica con la posición de Lenz, sino además con su ponderación de la psicología chilena. Se trata de un simultáneo interés, cariño y desprecio por los nativos de Chile, cuya fetichización ya se puede encontrar en Lenz. El filólogo se maravilla ante su objeto arqueológico (la cultura popular, el dialecto vulgar, el alma chilena), pero sus cultores son casi dispensables, en un deseo de depuración que se opone al desaseo premoderno que escupe sobre la ventana de su cátedra. Tal como explica Freud (1992 [1927]: 151-152), ante el objeto fetichizado el sujeto mantiene una actitud contradictoria: veneración y animosidad, ternura y hostilidad se dan simultáneamente ${ }^{26}$. A decir verdad, tal condición se cuela ya en los fundamentos ideológicos de los estudios folclóricos en general, tal como fueron expuestos por Raimund Kaindl en Die Volkskunde. Ihre bedeutung, ihre ziele und ihre methode [El folklore, su importancia, sus fines y su método] (1903), a quien Lenz, por cierto, cita latamente en su Programa de la Sociedad de Folklore Chileno (1909). Es esta subjetividad la que adquiere una relevancia mucho más evidente y determinante en las producciones literarias de Latorre. El amor condescendiente hacia el pueblo se puede leer ya en la pluma criollista de Federico Gana ( $c f$. Guerra 1987).

Si Lenz pone a disposición de Latorre una subjetividad con la cual identificarse y una perspectiva (incluso una metodología: los apuntes) sobre la realidad humana de Chile, es cierto también que Latorre modifica las coordenadas de lectura del archivo de la nación. Lenz es bastante

25 Este comentario no pasó desapercibido entre la intelectualidad de la época. Prueba de ello es que Julio Saavedra Molina, profesor del Instituto Pedagógico que se enfrentó con Lenz a propósito de la enseñanza de idiomas extranjeros, acusa en su Repeliendo la invasión (1908) que un profesor alemán habría afirmado: "hay dos cosas que me disgustan en Chile: demasiado barro y demasiados chilenos" (cit. en Subercaseaux 2007: 58).

26 Bajo esta luz, adquiere un nuevo sentido una broma que Lenz hizo en uno de sus viajes a la Araucanía. Para demostrar que podía incluso decir groserías en mapuzungun, entró en una ruca insultado a todos. Al ver que se molestaban, rió (Escudero 1963: 457-458). 
cuidadoso al considerar la teoría racial: esta no es el conjunto de premisas desde las que parte Lenz para sus investigaciones lingüísticas, sino que la raza funciona más bien como un horizonte de sentido flexible y que está aún por determinarse. Asimismo, desconsidera por entero el valor explicativo de factores como el clima y la geografía para dar cuenta de lo social: "todo eso son teorías y nada más; faltan absolutamente las pruebas" (1894: $116)^{27}$. Latorre, en cambio, suele atribuir todo comportamiento humano a la pertenencia racial y repone la clave fisiográfica, que considera conjuntamente la interpretación de la raza, de la geografía y del clima para develar el carácter de un grupo humano. Si en Lenz la raza es puerto de llegada que se construye durante la investigación, en Latorre corresponde a la estructura que ordena y predetermina el orden fenomenológico.

En su autobiografía, Latorre también propone el método que debería seguir una literatura auténticamente nacional, y aquí vuelve a su idea totalizante sobre la descripción de la vida del país en todos sus rincones. Plantea que se debe seguir el afán documentalista que marca la producción histórica y literaria de Chile. Lo más significativo para nuestros propósitos es que el concepto de documento como vía de acceso a la realidad le permite reunir a Lenz con Bello: recomienda sistematizar la idea de Lenz en el Instituto Pedagógico, esto es, que cada alumno, desde su cultura de proveniencia, contribuya a resolver algún problema "nacional, americano" (Latorre [1953]: 55); asimismo, retoma la convicción de Bello de aconsejar "el agotamiento de las fuentes históricas, desde la carta privada al artículo periodístico o al decreto oficial, para la futura interpretación de nuestra historia o de la de cualquier país de América" (55-56). Se trata de una "concepción planetaria del documento" (56) que extralimita la concepción primera de Lenz. Latorre parece buscar la archivación del mundo como totalidad de sentido y como totalidad sensible:

Y en esto reside, precisamente, todo el problema. / Las conversaciones, las escenas típicas, los artículos de costumbres, los reportajes, las cartas y todos los datos posibles sobre el clima; el color del verano o el del invierno o el ruido del viento y de los árboles o el silencio de la nieve y del agua de los lagos, todo eso, es material que no debe despreciarse. Al contrario es preciso buscarlo e interpretarlo a toda costa, como lo hacía Lenz (57).

\footnotetext{
27 Incluso cuando Lenz abraza la etnología como ciencia al interior de la cual desarrolla su investigación, y llega a afirmar que el clima influye en los modos de pensar del hombre, esto no tiene asidero teórico-metodológico alguno, y luego de su mención en el Programa de la Sociedad de Folklore Chileno no es retomado.
} 
En lo tocante al problema lingüístico, Latorre indica que para definir el criollismo debe referirse a un "problema filológico" (40). Acto seguido, cita "el espléndido diccionario de Lenz" para afirmar: "Pienso, como Lenz, que no podemos suplantar los vocablos americanos por términos peninsulares correspondientes. Es nuestra creación filológica y el substituirlos, sería como colocar un casco de acero en la cabeza de un indio o un trarilonco en la frente de un conquistador" (40). La metáfora de la vestimenta hace alusión a la misma diferencia y necesaria separación que Lenz postuló para las variedades de lengua. Acto seguido Latorre emplea otra metáfora, la que transparenta su aproximación al lenguaje vulgar: tras plantear equivocadamente que el término "Arauco" se debería a Ercilla y Zúñiga (autor del poema épico $L a$ Araucana) o a alguno de sus capitanes ${ }^{28}$, fantasea con que se debería a su instinto de poeta occidental: "vulgar origen del admirable Arauco de «La Araucana», en que la chirriante erre mapuche, al anteponerle el sufijo $a$, obra sobre el áspero sonido como el pedal sobre el piano" (41). Aunque peregrina, la fantasía etimológica revela el problema que tuvo Latorre con el lenguaje popular, al que consideraba demasiado tosco y cacofónico, según sugiere el "chirrido". Este lenguaje primitivo, entonces, debe someterse a una lima: la figura del pedal del piano remite a un tratamiento decididamente moderno (el piano se inventó recién hacia el siglo XVIII). La misma idea pesa sobre su comprensión de la cultura popular y del folclor en la literatura. Ya en 1912, comenzando su carrera literaria, afirma:

Pensé que la novela, según la frase de Balzac, es la historia de la vida privada de un pueblo; y que la vida, vista serenamente por una pupila equilibrada y encantadora debe pasar sin violencias a la realidad novelesca. En Chile sería este el papel del verdadero novelista, porque, en realidad, a excepción de algunas novelas de Blest Gana, nuestra vida permanece perfectamente ignorada (12, énfasis en el original).

"Nuestra vida" es aquí la vida del pueblo; es ella la que debe "pasar sin violencias a la realidad novelesca" que observa "una pupila equilibrada y encantadora", y este último adjetivo remitirá, en Latorre, a una estética naturalista-modernista. Es decir que el escritor ha de someter la realidad popular, de suyo primitiva y, por tanto, chocante, a un proceso de traducción estética que la vuelva asimilable por la sensibilidad occidental (como lo

28 Se trata de un error algo torpe, evidencia de que Latorre apenas ha leído el Diccionario etimológico que él mismo acaba de citar. Allí Lenz data el término en 1550, al encontrarlo en la tercera carta de Pedro de Valdivia al emperador Carlos V (Lenz 1979 [1905-1910]: 138). Ercilla arribó a Chile recién en 1557. 
notó también Benjamín Subercaseaux (1943)). Es en este punto acerca de la traducción que Latorre reintroducirá la perspectiva del hispanismo con inusitada fuerza.

\section{REGRESO ALARCHIVO: LITERATURA CON(TRA) FILOLOGÍA}

Latorre había tomado en 1929 la cátedra de Castellano del Instituto Pedagógico, esa que había iniciado Enrique Nercasseau y Morán en 1889 y que luego había continuado Julio Vicuña Cifuentes en 1925 (Figueroa 1929: 666). En su inspirada semblanza del maestro, Latorre vuelve a los grandes referentes de la literatura española (Cervantes, el Siglo de Oro y Fray Luis), pero además rescata la labor poética, la "prosa, espejo de puras aguas [...] del divino Fray Luis" (1916a: 31) del que fuese el primer profesor de literatura española de América Latina ${ }^{29}$. Nercasseau y Morán había sido contratado en 1888 por la Facultad de Humanidades como "profesor extraordinario de Literatura Superior, General y Española" (cit. en Arabena Williams 1950: 24). Ese mismo año participó en la fundación de El Ateneo $\mathrm{y}$, como uno de los "primeros cruzados del hispanismo" (27), de la Unión Iberoamericana, dedicada a recomponer el vínculo de Chile con España. Al asumir la cátedra en el Instituto Pedagógico, formó en paralelo una academia dedicada al estudio de autores españoles clásicos ( $c f$. "Academia del Instituto Pedagógico" 1890). En la época de Latorre, el hispanismo gozaba de buena salud en las crestomatías y antologías del parnaso español a cargo de Fidel Pinochet Le Brun. Incluso antes de que la Academia Chilena de la Lengua retomara sus funciones en 1915, ya había una fuerte recomposición del hispanismo en los círculos académicos chilenos, y Latorre fue afecto a esta sensibilidad.

Si la faceta poética de Enrique Nercasseau y Morán provoca el encendido elogio de la España clásica y conquistadora, algo similar encontramos en una reseña de 1914 a La Quintrala, novela de Antonio Bórquez Solar. Allí Latorre da rienda suelta a su hispanismo ${ }^{30}$ :

29 Desde 1896 enseñó Historia literaria y Literatura preceptiva (Lenz 1912: 6).

30 El hispanismo, ideología y estrategia de diplomacia cultural con la que España pretendió mantener influencia sobre las excolonias de América Latina desde la década de 1820, involucra tres ideas: "The existence of a unique Spanish culture, lifestyle, characteristics traditions and 
Bórquez es, ante todo español de raza; y literariamente es el mismo español que, alejado de la madre patria, conserva y ahonda por medio de la conciencia artística, las cualidades psicológicas del escritor peninsular. Dentro de él tiene vivo al capitán aventurero del cual desciende, que rezaba en las noches australes y leía el Quijote con campanuda complacencia.

Nadie lo aventaja, seguramente, en este sabroso aroma clásico que duerme como el bouquet de un vino primoroso, en sus frases nerviosas y elásticas.

El racismo hispanófilo fue bien captado por Antonio Romera (1974), quien recuerda la hispanofilia de Latorre como más emocional que intelectual o libresca. Tal hispanismo no decaerá en los extensos ensayos sobre literatura que publica el criollista desde 1929, ya como profesor universitario. La fijación en una ascendencia que se desea ilustre será promovida por el naturalismo y reforzada luego por la lectura de Raza chilena (1904) de Palacios. Una de las principales figuras que rescata Palacios es la del conquistador español, llamado "padre de la raza" (1918 [1904]: 35), cuya mayoría habría preservado intacta su ascendencia goda: "Por los numerosos retratos o descripciones que conozco de los conquistadores de Chile, puedo asegurar que a lo sumo el diez por ciento de ellos presentan signos de mestizaje con la raza autóctona de España, con la raza ibera; el resto es de pura sangre teutona, como Pedro de Valdivia, cuyo retrato es tan conocido" (36). La teoría de Palacios permite entender por qué Latorre vuelve una y otra vez sobre Alonso de Ercilla y Zúñiga. El autor de La Araucana es, como Latorre, también vasco, lo que le permite al criollista inscribirse en la tradición de literaria nacional a partir de y en línea directa con su mismo fundador. En "Ercilla, aventurero de la conquista" (1933), lo retrata como "un niño rubio [...] de rancia estirpe vizcaína. [...] Como Elcano y Loyola, Ercilla es un vasco embrujado por Castilla, pero sus características raciales no se desmienten ni en su obra ni en su temperamento" (Latorre 1933: 57). Latorre vuelve sobre Ercilla y/o sobre la conquista en otros dos textos ( $c f$. Latorre $\left.1936,1938^{31}\right)$, pero lo que más interesa de esta cita es que hace referencia a

values, all of them embodied in its language; the idea that Spanish American culture is nothing but Spanish culture transplanted to the New World; and the notion that Hispanic culture has an internal hierarchy in which Spain occupies a hegemonic position" (Del Valle 2002: 6). El hispanismo fue la única estrategia que restó a España para mantener un imperio cultural sobre la región tras la derrota en la guerra con Estados Unidos en 1898, conflicto bélico que, además de mostrar el poderío de este último, sepultó las posibilidades de intervención militar y económica de la primera (6-7).

31 La obsesión racial en clave hispanista llega a extremos difícilmente superables en una columna de Sucesos de 1913. Allí su autor, “Tijera”, afirma que Maluenda se jacta de 
un aspecto clave de lo que para Zola correspondía a la creación artística. Si Latorre puede afirmar que a inicios de siglo sabía de memoria la definición del francés de una obra de arte -"Novela, poema, cuadro o escultura no es sino un rincón de la naturaleza, visto a través de un temperamento" ([1953]: 32 , énfasis en el original)-, entonces ese temperamento es justamente lo que encuentra en el poeta-conquistador, que reúne sensibilidad y virilidad. ¿Qué consecuencia tiene todo esto para la representación de lo popular en la literatura de Latorre?

Si consideramos sus producciones literarias tempranas, observaremos que en su primer volumen de relatos, Cuentos del Maule (1912), hay una mirada cercana a la autobiografía, que romantiza el paisaje y denuncia a la oligarquía, pero ya se encuentran observaciones denigratorias vinculadas a una perspectiva fisiográfica de lo popular: "Envueltos en un paisaje tan estéril e insoportable, los habitantes de estos lomajes tienen un salvajismo nativo: su inteligencia es pequeña e incapaz de sobreponerse a la pobreza del medio" (1912: 67). Luego, se retrata a la joven protagonista del cuento como semejante a las demás muchachas del campo, que producen la "impresión de asco de todas las campesinas harapientas" (68). En su siguiente libro, Cuna de cóndores (1918), el narrador fuertemente autobiográfico es reemplazado por una perspectiva omnisciente de un naturalismo mucho más pronunciado. Es aquí que hace su entrada la teoría de Palacios, a la que el narrador se apega celosamente en numerosos pasajes. En "La cordillera es sagrada" se realiza una crítica social a la oligarquía a través de la historia de vida de don José María Mardones, veterano de la Guerra del Pacífico que va a morir al templo natural, donde es purificado. "Risquera vana" relata la vida de Nicomedes Román, condenado al vagabundaje por el campo después de matar a un gañán. Tanto este, huaso, como el primero, roto, portan la

descender puramente de los indígenas de Chile, al punto que el bandolero Ciriaco Contreras sería antepasado suyo por línea directa. Luego dice haber consultado al "conocido etnólogo Mariano Latorre [!]" (1913: 19) y que este le aseguró que Maluenda tenía una porción de sangre vasca, para complementar con un comentario que lo liga a sí mismo, descendiente de vascos: "Los vascos son leales, sinceros, toscamente bellos" (19). La identificación racial de Latorre parece haber sido cultivada como una imagen pública, a juzgar por numerosos testimonios de escritores: Merino Reyes lo recuerda como un "[h]ombre elegante, con el vestir de un caballero español" (1986: 37); Livacic, como "un Adelantado en el descubrimiento de la fibra artística de su tierra" (1986: 3); Joaquín Edwards Bello lo observa como "un príncipe de a pie. Príncipe berger. Príncipe ambulante y sabio. Príncipe pastor. Me parece que entraba en los escenarios del Sur como si fueran su parque, su fundo propio [...] Amó a Chile como lo amaron los conquistadores. Amó la tierra virgen, como el hombre blondo y blanco ama la carne morena. De ese enamoramiento murió Mariano. Deliraba con nuevo viaje al campo la mañana misma de la partida" (1955: s/p). 
valiente sangre mapuche. De Mardones se dice: "Raza chilena era su Biblia, y con ella bajo el brazo vagaba en los veranos" (Latorre 1918: 130). Los personajes - mestizos chilenos- tienen todos los valores, creencias, actitudes y psicología que Palacios le asigna al individuo nacional: individualismo, egoísmo, militarismo, fortaleza física, superstición, resiliencia, entre otras.

Ahora bien, esa teoría también sufre cambios. La principal diferencia reside en que Latorre es ambiguo al considerar al mapuche y al mestizo. Los comentarios peyorativos hacia los personajes populares se acentúan: las mujeres son presa de "la demencia enardecida de su sangre. La hembra instintiva despertaba en ella con sus dulces arrebatos de esclava" (24); de un bandido se dice: "En su naturaleza casi animal dormía en germen el individualismo bravío de los araucanos, el aislamiento primitivo de las razas sin porvenir" (32); "Moñi se siente desfallecer: un sopor helado oprime sus párpados, pero su ruda vitalidad de indígena reacciona con histérico arrebato" (62); sobre un árbol: "Lentamente el fuego lengüeteó por los duros nervios del tronco, deforme y cabelludo como una cabeza de indio" (213); sobre las creencias populares: "la superstición, vago instinto religioso, rodea sus almas primitivas" (93); sobre la psicología del chileno: "esa gloria falsa que es la esencia misma del alma chilena" (100).

Es en Zurzulita (1920), su primera novela, que Latorre alcanza una distancia aún mayor respecto de lo popular. La novela relata la historia de Mateo Elorduy, joven poeta abúlico e hiperestésico que debe hacerse cargo de una hacienda tras la muerte de su padre. La ilusión de una vida idílica en el campo es alimentada por la expectativa de un amor con Milla, la maestra de la escuela; Mateo se batirá a duelo con el administrador del fundo por ella. Cuando ha decidido volver a la ciudad y abandonar la lucha, será asesinado. De acuerdo con la estética naturalista, los personajes son retratados a partir del determinismo absoluto de la raza y del medio. La teoría de Palacios sirve aquí para explicar la ascendencia de los campesinos, que se retrotrae a la conquista española, pero en clave grotesca y corrupta.

En los tres episodios folclóricos que se relatan - el velorio del angelito, la vendimia y la procesión de San Francisco-, escenas colectivas, Mateo es retratado como un ser ajeno que, sin embargo, realiza algún esfuerzo por incorporarse a los ritos. En todos ellos se comienza la narración con objetividad, pero luego la escena se estropea, invariablemente, en la borrachera inconsciente que sirve para su condena definitiva. En el velorio encontramos una descripción cuidadosa del niño muerto -sus ropas, maquillaje y postura- y de los diferentes momentos del ritual, así como una transcripción de los versos que se le dedican. La mirada documental es matizada por comentarios del tipo: "Parecía una estatuita cristiana que hubiera caído en manos de una tribu salvaje" (Latorre 1973: 236) o "sus 
caras hirsutas [las de las mujeres] aparecen diabólicamente iluminadas por los leños encendidos" $(242)^{32}$. En el escenario festivo de la vendimia se comienza del mismo modo, describiendo la faena campestre, pero pronto comienzan los adjetivos y epítetos enjuiciadores: "Envueltos en la grisalla malva del amanecer aparecían como bultos informes, apelmazados pelotones de sombra azulosa" (277); un hombre trabajando en el proceso del vino realiza una operación con "la gravedad de un rito religioso, el bailoteo grotesco de un indio" (281). Termina la vendimia y comienzan "las risotadas burdas de las mujeres" (284), la "cínica burla" (287) de un refrán popular, la "voz desabrida y chillona" de un cantor (289), la "burda guitarra y la primitiva letra" (289) de una cueca; en fin, el capítulo cierra con una comparación entre los hombres y los cerdos, en la borrachera humana generalizada, a la que se une el embragamiento de los chanchos y su "crispante grito de desollamiento" (290). Por último, en la procesión de San Francisco, por vez primera Mateo parece unirse al todo, formar parte de un colectivo; sin embargo, al terminar vuelven las imágenes grotescas -los campesinos forman "un solo organismo monstruoso que corría en pos del milagro con ciega y desesperada fe" (307) - y al joven le parece que "ha salido de una pesadilla" (311). La representación de los temas folclóricos como bárbara y grotesca extrema los postulados evolucionistas en que Lenz basaba su labor como folclorista ${ }^{33}$. Si el filólogo puede vivir la cultura popular desde su manifestación artística y elidir a los sujetos que la producen, esto ya no será posible para el escritor, cuyo mandato naturalista lo lleva a representar la experimentación directa del fenómeno cultural, y ya no su versión depurada. De acuerdo al ideal de Zola, Zurzulita se pretende "documento humano", y al hacerlo devela la cualidad invivible de lo popular in situ. La novela es representación de un calvario, pero también se ofrece como objeto a partir del cual el lector mesócrata de la ciudad puede vivir vicariamente una experiencia límite y obtener un conocimiento, sin que ello desestabilice su posición.

En términos lingüísticos no solo hay una separación entre la norma culta y la popular, sino que la primera corresponde a la variedad peninsular. Como ha notado Andrés Gallardo, el léxico y la sintaxis de la voz narrativa hacen

32 Para Goic, esta escena simplemente “deriva en una repulsa de la bárbara tradición popular al detenerse en el detalle grotesco y horroroso" (1971 [1968]: 106).

33 Si se lee la novela en clave alegórica, bien podría pensarse que este nivel de condena se intensifica por la función que cumplen los personajes del cura, el cura civil y el administrador en tanto figuraciones de la clase política chilena y del sistema parlamentario en particular. El punto es atendible, pero insuficiente para explicar el nivel de animosidad que advierto en el texto; me acerco entonces a Goic (1971 [1968]), quien la atribuyó al binomio civilización/ barbarie que estructura el mundo representado en la novela. 
parte de la tradición literaria española ${ }^{34}$; estéticamente, la novela bebe de la tradición modernista (Morales 2005 [1965]), de gran estilización, y de la naturalista. Es decir, en Latorre se profundiza el divorcio entre lo alto y lo bajo que ya observamos en Lenz. En contraste, el habla chilena aparece como inculta, razón por la cual no se halla "una decidida incorporación del español de Chile como sustrato que sustente el texto mismo de los relatos" (Gallardo 2011: 25). De ahí la predilección por figuras retóricas y motivos populares y géneros como el refrán, el dicho, la paya y la décima. De ahí la reacción ante el lenguaje campesino: "Volvían nuevamente las carcajadas a cada respuesta del pequeño, terminadas en es qué, curiosa forma interrogativa de sus respuestas" (Latorre 1973: 31, énfasis en el original) o la anotación que simula su fonética: "Hay uvas qu'es un gusto. Es sabío que l'uva de tierra colorá da un vino güenazo... Harto que mi'ha costao cuidarlas. Todos los días tengo que tapar aujeros por ey..." (263). A pesar de esa distancia, también hay emoción ante el espectáculo de la lengua viva: "Aún resuena ese di 'ay en sus oídos, barbarismo que, envuelto en la entonación melodiosa de su voz, cobra un encanto original" (88, énfasis en el original). En este sentido, el archivo más evidente que elabora Zurzulita (aunque no el único) es el glosario incorporado al final de la novela. Allí se explican términos según su procedencia (mapuche o quechua) y su clasificación (chilenismo $\mathrm{o}$, en dos casos, neologismos creados por Latorre ${ }^{35}$ ), así como el significado de ciertas frases hechas: "comer maqui y sacar huira", "poner las peras a cuatro", "póngale qu'es di'uva".

El hispanismo de Zurzulita también puede observarse en la dimensión del género. El protagonista, de sensibilidad enfermiza, es una verdadera sátira del modelo de poeta modernista o sentimental. Nada más alejado a la idea de un conquistador. Sin embargo, y en sintonía con los postulados naturalistas, Mateo recobra el brío de su raza toda vez que siente el contacto con la tierra:

Y una oculta fuerza lo vigorizaba, una fuerza oculta que hacía correr la sangre en oleadas viriles que ensombrecieron su cabeza y que, de golpe, lo compenetraban con el medio rústico, haciendo nacer en su espíritu desconocidas raíces de lucha, ante las cuales on Carmen Lobos

34 Tanto Carlos Silva Vildósola (1920) como Benjamín Subercaseaux (1943) y Ricardo Latcham (1952 [1949]), prologuistas de distintas ediciones de la novela, destacaron el empleo y manejo del castellano castizo y del estilo español, combinado con la técnica de narradores franceses y anglosajones.

35 Estas palabras son creadas a partir de la emulación de voces extranjeras ("bruina" y "grisalla", préstamos del francés), onomatopeyas ("cliqueteo", de "clic clic"), o bien desde las raíces hispánicas de los términos: caso del verbo "hojecer", de echar hojas (1973: 343-346). 
quedaba reducido a proporciones naturales y el campo, dócil, obedecía a su esfuerzo como una bestia domesticada (46).

Es decir, Mateo presenta dos caras: la del poeta afrancesado y abúlico y la del conquistador decidido y viril, hijo de un "vasco silencioso" (9) que había sido marino contrabandista. Como explica Subercaseaux (1997: 50), por estos años la sensibilidad dominante, el nacionalismo, semantiza los géneros del siguiente modo: el masculino se identifica con la ciencia, el pragmatismo, el espíritu guerrero, el rescate de la realidad y de lo vernacular; mientras que lo femenino es sinónimo de afrancesamiento, ocio, aristocracia, ineficiencia. Ahora bien, en el mismo Mateo se anudan marcas de género femenino, pero que escapan a la semantización recién referida. Nótese que la madre de Mateo no es mencionada jamás, no existe como personaje en el texto. Esta madre es reinscrita en él de diferentes maneras. Su más clara huella es de naturaleza onomástica: en primer lugar, el nombre de pila, Mateo/Mater; luego, el apellido, en que se cuela un significante de orden referencial: Elorduy es el apellido de la abuela paterna de Latorre (cf. González Colville 2002: 10); el término, de origen vasco, se forma por la raíz el(h)orri, "espino", y el sufijo dui, que denota muchedumbre (Michelena 1953: 58, 60). Significa, pues, "espinar". Las tres referencias de este apellido indican una genealogía familiar y cultural: la madre, la naturaleza y España, país de origen de Latorre al que vuelve obsesivamente en sus ensayos, como lo vimos. Mateo es entonces un conquistador que lleva en su frente la seña de la madre patria, que le rinde tributo al enfrentarse a la barbarie. Es sin embargo un conquistador ocasional, inconstante.

El hecho de que Mateo muera, de que su conquista falle, podría inducirnos a leer una reivindicación de la tierra chilena ante el conquistador español. Sobre todo porque la tierra es en la novela la figuración del indígena por excelencia (no es sinónimo de pasividad). El caso más elocuente es el del monte Gupo, que lleva el mismo nombre que el antiguo cacique de la zona y que, junto con Name, es antropomorfizado: "En medio de esos montones azules perfilábase un cono de largos taludes, el cerro Name, que, frente a Gupo, parece custodiar el rebaño de las montañas, como dos caciques membrudos sobre su tribu" (Latorre 1973: 26). Esta lectura no deja de tener interés, pero lo cierto es que la muerte de Mateo no implica la derrota de la virilidad como valor textual. La femineidad ha vencido en la diégesis, pero no en el nivel de la enunciación narrativa, que ya vimos en qué variedad lingüística se afinca. Por otra parte, aun cuando el narrador adopte muchas veces el punto de vista de Mateo, en otras ocasiones se independiza y hace comentarios que transparentan su posición ante la narración. En otras palabras, en virtud de la muerte de Mateo, la conquista se traslada a la voz narrativa. Sobre un "viejo sentencioso" que es el único hombre sobrio del 
velorio se dice: "Era una cabeza de nobles líneas. [...] Una barba rizosa enmarcaba sus facciones severas de hidalgo español" (245); sobre el zarandero de la vendimia: "era el tipo verdadero del roto chileno, sin mezcla de araucano, con su nariz de águila, vagamente árabe" (280). Hay aquí una celebración ya no del mestizo, sino de la figura colonial del criollo: español nacido en Chile.

Detengo el comentario de la novela aquí, pues no pretendo dar una interpretación acabada de aquella, sino tan solo relevar los puntos que se conectan con los problemas tratados en el acápite primero.

\section{CONCLUSIONES}

Uno de los puntos más interesantes -a mi parecer- de la evolución que los postulados de Lenz describe en los escritos de Latorre es la decidida reincorporación del hispanismo como ideología que configura no solo la autorrepresentación y la imagen pública del escritor, sino además la subjetividad de sus narradores, que semejan conquistadores españoles. Esta interpretación, al parecer dominante en la época en que Latorre hizo su obra, se encuentra hoy olvidada en parte debido al escaso interés de la crítica especializada por el criollismo. Si retomo esta lectura no es para volver a un impresionismo acrítico, que simplemente transfiera las cualidades psicológicas del autor a la voz narrativa dominante en sus textos, sino para revisitarla críticamente. Releer este hecho hoy permite enriquecer y complejizar nuestra comprensión del criollismo. La reacción contra la modernización "afrancesada" no solo significó volver el rostro hacia el mestizo y lo popular como claves de interpretación de la comunidad y la cultura nacionales, sino que además recuperar un vínculo cultural con España, que fue identificada con un sentido de pureza racial, tradición, virilidad, voluntad y prestigio. En virtud de esa recuperación, estos sentidos le son arrebatados a la idea de lo vernáculo, la cual es vista de manera inferior, en falta. El hispanismo de Latorre permite ver en qué medida se distanció de la lección de Lenz (y de Palacios) o, quizás, cuánto extremó posiciones que ya estaban en la aproximación de Lenz a la cultura popular.

Poblete mostró en qué medida Lenz redefinió "lo literario" (2003: 253) al dignificar la palabra popular, pero aquí hemos considerado también la posición privilegiada de la tradición literaria española que reconoció Lenz para la formación de un lenguaje nacional. Esto fue retomado y profundizado 
por Latorre, quien además proyectó en Lenz su subjetividad de inmigrante. Al reinstalar la mirada del conquistador español como eje de identificación del criollo, reinscribió la prerrogativa que Bello, rescatando la épica, había intentado con su lectura del Poema del Cid y de La Araucana. La filiación de Latorre en esa mirada colonialista y fundacional, posibilitada por la matriz epistémica del naturalismo, fue percibida tan solo en su carácter nacionalista; el prólogo de Omer Emeth a Cuna de cóndores "revivió en el ambiente literario de Chile la impresión que había producido, en 1842, Lastarria con su discurso inaugural" (Silva Castro 1961: 371). Un análisis de la posición enunciativa del narrador genérico de Latorre ya en su primera etapa productiva da cuenta de una posición subjetiva (y de una construcción de mundo, sobre todo en Zurzulita) que vuelve obsesivamente sobre España como matriz de identificación cultural y sobre la conquista como su escena fundante. Este hecho reenfoca la significación histórica de la obra de Latorre en el contexto de la tradición literaria chilena al revisitar el sentido que la épica tiene en su literatura, una épica que ya no corresponde al mundo narrativo, sino a la posición desde la que el relato es construido.

Una primera aproximación al archivo de Lenz podría asumir que, por reunir materiales de origen popular, dejaba fuera o se oponía a ese otro archivo que inició Bello. La tensión que se podría suponer entre ambos archivos es, sin embargo, resuelta por Latorre, cuyo planteamiento de una continuidad metodológica basada en un documentalismo positivista pretende ponerlos a colaborar. Esta solución técnica nos hace volver la vista sobre la dinámica ideológica del archivo, que justamente neutraliza la heterogeneidad constitutiva de sus materiales. Ahora bien, el archivo de Lenz tampoco estuvo exento de estas tensiones hermenéuticas: Vicuña Cifuentes y Laval fueron miembros de la Academia Chilena de la Lengua en su período de recomposición, que comienza en 1915 y que vuelve a refrendar la hegemonía cultural ibérica y tópicos decimonónicos como la unidad de la lengua y la corrección lingüística. Este gesto transparenta su conservadurismo cultural en un momento sociopolítico convulsionado por la "cuestión social" y el auge de movimientos políticos comunistas, anarquistas y socialistas (Cifuentes 2018: 372). De hecho, autores de tendencia vernacularista como Samuel Lillo o Díaz Garcés también eran miembros de instituciones hispanistas: la Unión Iberoamericana y la Academia Chilena de la Lengua. Aun cuando la alianza entre el folclorismo pretendidamente democratizante de la Sociedad Chilena de Folklore y la tradicional postura aristocrática de la Academia Chilena de la Lengua no sea una sorpresa -el folclorismo francés nace a mediados del siglo XIX, de hecho, como iniciativa policial que busca exorcizar un peligro revolucionario (De Certeau 2004: 47-48, 53)-, su consideración situada en el Chile del siglo XX (apenas esbozada aquí) entraña complejidades que 
le son propias. La significación de Nercasseau y Morán para Latorre, entre otras evidencias, nos llevó a relacionar hispanismo con criollismo, cuya posición mesócrata y con vocación de masas lo hizo negociar el lugar del lenguaje en un concepto de nación que pretendía defenestrar al oligárquico.

El archivo antropológico que Lenz y Latorre defendieron, con base en el folclor, es problematizado en Zurzulita; su misma hechura resulta en entredicho por la distancia entre narrador y personajes, distancia atravesada por un afecto sobre todo negativo hacia lo popular. Lenz, filólogo, pretende objetividad e imparcialidad en la observación de lo popular; Latorre, escritor naturalista, sigue los dictados de Zola acerca de la creación literaria. De ahí que necesariamente reponga el factor subjetivo, que se relaciona dialécticamente con el objetivo. Si en su primer volumen de relatos prima la subjetividad, en el segundo la objetividad cientificista dominará; en Zurzulita, en tanto, se dará una singular síntesis, en que la reacción subjetiva es justificada con argumentos positivistas. Cabe aquí otra diferencia entre las miradas de Lenz y Latorre respecto de la cultura popular: si Lenz busca estudiar la dinámica psicológica del chileno desde sus manifestaciones orales, Latorre busca transmitir una experiencia de lo popular desde su inmersión en la cultura. Es en virtud de esta diferencia de distancias que la psicología del chileno es reducida por Latorre a un puñado de categorías norteadas por el "primitivismo". Latorre se distancia del sujeto popular porque antes se ha acercado demasiado. Bajo esta luz, el pensamiento de Latorre se aleja un tanto del Partido Radical y se acerca al de Francisco A. Encina en Nuestra inferioridad económica (1911), por vía del racismo de Palacios ( $c f$. Gazmuri 1981) que compartía con el escritor criollista la inferioridad de la raza indígena y la superioridad de la vasca ( $c f$. Barr-Melej 2001: 86, 245). Como ha dicho Patrick Barr-Melej (2001: 78), el criollismo es antirrevolucionario y antioligárquico, pero en Latorre este último carácter se debate con su tendencia hacia posiciones culturales más conservadoras.

\section{REFERENCIAS BIBLIOGRÁFICAS}

Alemany Bolufer, José (Dir.). 1917. Diccionario de la lengua española. Barcelona: Sopena. Alonso, Carlos J. 1990. The Spanish American Regional Novel. New York: Cambridge University Press.

Arabena Williams, Hermelo. 1950. Don Enrique Nercasseau y Morán (1854-1925). Anales de la Universidad de Chile 77-78, serie 4: 7-59.

Academia del Instituto Pedagógico. 1890. Sesión de apertura en 20 de junio de 1890. Santiago: Imprenta Victoria de H. Izquierdo y Ca. 
Arcos, Carol y Andrea Kottow. Sociabilidad literaria. Historia crítica de la literatura chilena. Vol. II. La era republicana. Independencia y formación del estado nacional, pp. 375-396. Bernardo Subercaseaux (coord.). Grínor Rojo y Carlos Arcos (eds.) Santiago: Lom Ediciones.

Barr-Melej, Patrick. 2001. Reforming Chile: Cultural Politics, Nationalism and the Rise of the Middle Class. Chapel Hill: University of North Carolina Press.

Baguley, David. 1990. Naturalist Fiction. The Entropic Vision. Cambridge: Cambridge University Press.

Cáceres, Valentina, José Miguel Ortiz y Darío Rojas. 2020. El Diccionario etimológico de Rodolfo Lenz (1905-1910): una aproximación glotopolítica. Boletín de Filología 55/1: 13-49.

Cañas Pinochet, Alejandro. 1903. Escenas de la vida agrícola en ultra-Maule. Santiago: Imprenta Cervantes.

Catalán, Gonzalo. 1985. Antecedentes sobre la transformación del campo literario en Chile entre 1890 y 1920. Cinco estudios sobre cultura y sociedad, pp. 71-175. José Joaquín Brunner y Gonzalo Catalán. Santiago: FLACSO.

Cifuentes, Juan. 2018. Ideologías lingüísticas en Chile: el Boletín de la Academia Chilena de la lengua (1915-1931). Logos: Revista de Lingüística, Filosofia y Literatura 28/2:361-376.

Concha Ferreccio, Pablo. 2019. Trasplantes del espíritu: folclor y lengua nacional en Rodolfo Lenz. Boletín de Filología LIV/1: 119-151.

Corominas, Joan. 1980. Diccionario crítico etimológico castellano e hispánico. Con la colaboración de J. A. Pascual. Madrid: Gredos.

Dannemann, Manuel. 2010. Tres buscadores de la chilenidad: Lenz, Laval y Vicuña Cifuentes. Anales de Literatura Chilena 14: 57-92.

De Certeau, Michel, Dominique Julia y Jacques Revel. 2004. La belleza del muerto. La cultura en plural. Buenos Aires: Nueva Visión.

Del Valle, José. 2002. The Battle over Spanish between 1800 and 2000. Language Ideologies and Hispanic Intellectuals. New York: Routledge. 1: 17-39.

2017. La perspectiva glotopolítica y la normatividad. Anuario de Glotopolítica

DerridA, JACQues. 1997. Mal de archivo. Una impresión freudiana. Trad. Paco Vidarte. Madrid: Trotta.

Edwards Bello, Joaquín. 16 de septiembre de 1955. Mariano Latorre. La Nación: s/p.

El HimNo A LA Flor NACIONAL DE ChILE. 29 noviembre 1919. Zig-Zag 771: s/p.

EnNis, JuAn ANTONIO. 2015. Del retorno a un nuevo origen: filología, exilio y nación en el Cid de Bello. Return Migration in Romance Cultures, pp. 103-126. Andreas Gelz y Marco-Thomas Bosshard (eds.). Freiburg: Rombach.

Escudero, Alfonso. 1963. Rodolfo Lenz. Thesaurus XVIII: 445-484.

FerrecCio, Mario. 1979. Presentación. Diccionario etimológico de voces chilenas derivadas de lenguas indígenas americanas. Rodolfo Lenz. Edición dirigida por Mario Ferreccio Podestá. Santiago: Seminario de Filología Hispánica, Universidad de Chile.

Figueroa, Virgilio. 1929. Diccionario histórico y biográfico de Chile 1800-1925, vols. III, IV, v. Santiago: Imprenta y Litografía "La Ilustración".

Foucault, Michel. 1968 [1966]. Las palabras y las cosas. México: Siglo Xxi.

Freud, Sigmund. 1992. [1927]. El fetichismo. Obras completas, vol. XXVII, pp. 141-152. Trad. José Luis Etcheverry. Buenos Aires: Amorrortu.

GALLARDO, ANDRÉs. 2011. Dos formas de recuperación de la oralidad en la narrativa chilena. Anales de literatura chilena 15: 13-27.

García, Eladio. Los libros en la universidad. Las Últimas Noticias. 2 oct. 1971, s/p. 
GAZMURI, CRistián. 1981. Notas sobre la influencia del racismo en la obra de Nicolás Palacios, Francisco A. Encina y Alberto Cabero. Historia 16/1: 225-247.

Gorc, Cedomil. 1971 [1968]. V. Zurzulita. La novela chilena. Los mitos degradados, pp. 97-123. $3^{\circ}$ ed. Santiago: Universitaria.

González Colville, Jaime. 11 de octubre de 2002. El parralino Neruda. Diario El Centro: 10.

González Echevarría, Roberto. 1998. Mito y archivo. Una teoría de la narrativa latinoamericana. México: FCE.

GuERRA, LuCíA. 1987. Crisis de la identidad cultural y génesis del criollismo: visión oficial del campesino en la cuentística de Federico Gana. Texto e ideología en la narrativa chilena, pp. 49-63. Minneapolis: The Prisma Institute.

Hale, Charles. 2000. Ideas políticas y sociales en América Latina, 1870-1930. Historia de América Latina. Vol. 8. Cultura y Sociedad, 1830-1930, pp. 1-64. Ed. Leslie Bethell. Barcelona: Crítica, 2000.

Laplanche, Jean y Jean-Bertrand Pontalis. 1996 [1967]. Diccionario de psicoanálisis. Barcelona: Paidós.

Latcham, Ricardo. 1952 [1949]. Prólogo, pp. 5-12. Zurzulita. Mariano Latorre. 5a ed. Santiago: Nascimento.

1953. Discurso de recepción a don Mariano Latorre Court. Universidad de Chile. Facultad de Filosofía y Educación. Discursos académicos pronunciados en la sesión del Honorable Consejo Universitario celebrada para recibir al Miembro Académico de la Facultad de Filosofía y Educación señor Mariano Latorre Court, pp. 43-55. Santiago.

Latorre, Mariano. 1912. Cuentos del Maule. Santiago de Chile: Zig-Zag.

[1953]. Autobiografía de una vocación; Algunas preguntas que no me han hecho sobre el criollismo. Santiago de Chile: Ediciones de los Anales de la Universidad de Chile. 20 agosto 1914. Bórquez Solar. Sucesos 621: 21.

14 octubre 1915a. El doctor Lenz. Sucesos 681: s/p.

25 noviembre 1915b. Galdames. Sucesos 687: 38.

3 febrero 1916a. Don Enrique. Sucesos 697: 31.

23 marzo 1916b. Don Rubén. Sucesos 704: 11.

Cuna de cóndores. 1918. Santiago: Imprenta universitaria.

[1936] 1971. El huaso y el gaucho en la poesía popular. Memorias y otras confidencias, pp. 261-294. Selección, prólogo y notas de Alfonso Calderón. Santiago: Andrés Bello.

1973 [1920]. Zurzulita. 9a ed. Santiago: Nascimento.

Lenz, Rodolfo. 1890. Lecciones sobre el lenguaje. De la clase de Castellano del Dr. Lenz. II año. Santiago. Disponible en: http://www.memoriachilena.gob.cl/602/w3-article-546517. html

1894. Ensayos filolójicos americanos I y II. Anales de la Universidad de Chile 87: 113-132; 353-367.

1899a. Memoria sobre las tendencias de la enseñanza del idioma patrio en Chile. Santiago: Imprenta Cervantes.

1889b. Proyecto de programa de castellano. Santiago: Imprenta Cervantes.

1919 [1918]. Sobre el estudio de idiomas. Cartas al señor Julio Saavedra Molina.

Santiago: Imprenta y Litografía Barcelona.

1909. Programa de la Sociedad de Folklore Chileno. Santiago: Imprenta y Encuadernación Lourdes.

1912. ¿Para qué estudiamos gramática? Santiago: Imprenta Cervantes.

1919 [1895]. Sobre la poesía popular impresa de Santiago de Chile: contribución al folklore chileno. Anales de la Universidad de Chile 144: 511-622. 
1979 [1910]. Diccionario etimológico de voces chilenas derivadas de lenguas indigenas americanas. Edición dirigida por Mario Ferreccio. Santiago: Seminario de Filología Hispánica, Universidad de Chile.

s/f. Anexo segundo al Diccionario Etimolójico de Voces Chilenas derivadas de lenguas indíjenas americanas. Publicación privada del autor.

Livacic, ERneSto. 23 sept. 1986. Mariano Latorre, descubridor del campo chileno. La Prensa Austral: 3.

Locane, Jorge. 2019. Crítica cultural y glotopolítica. Introducción. Theory Now 2.2: 1-3.

Merino Reyes, Luis. 1986. Centenario de Mariano Latorre. Occidente 316: 36-38.

Michelena, Luis. 1953. Apellidos vascos. San Sebastián: Editorial Icharopena.

Molina NúÑEZ, Julio y Juan Agustín Araya. 1917. Selva lírica. Estudios sobre los poetas chilenos. Santiago: Sociedad Imprenta y Litografía Universo.

MoRALES, LeONIDAS. 2005 [1965]. Imagen literaria e imagen convencional en los cuentos de Manuel Rojas". Manuel Rojas. Estudios críticos, pp. 135-149. Selección y prólogo de Emmanuel Tornés y Naín Nómez. Santiago: Editorial Universidad de Santiago.

Palacios, Nicolás. 1918 [1904]. Raza Chilena. 2a ed. Santiago: Editorial Chilena.

PAVEz, JoRge. 2015. Laboratorios etnográficos. Los archivos de la antropología en Chile (1880-1980). Santiago: Ediciones Universidad Alberto Hurtado.

Poblete, JuAn. 2003. "El castellano: la nueva disciplina nacional”. Literatura chilena del siglo XIX: entre públicos lectores y figuras autoriales, pp. 209-266. Santiago: Cuarto Propio.

Ramos, Julio. 1989. Desencuentros de la modernidad en América Latina. México: FCE.

Rodríguez Adrados, Francisco. 1970. Nietzsche y el concepto de la filología clásica. Habis 1: 87-105.

Rodríguez Freire, Raúl. 2015. Sin retorno. Variaciones sobre archivo y narrativa tatinoamericana. Adrogué: La Cebra.

Rodríguez-Navas y Manuel Carrasco. 1918. Diccionario general y técnico hispanoamericano. Madrid: Cultura Hispanoamericana.

RoJAS, DARío. 2017. Representaciones del cambio lingüístico en Chile durante el siglo XIX: ¿progreso o decadencia? Literatura y Lingüística 36: 243-262.

Romera, Antonio. 24 de abril de 1974. Mariano Latorre y su hispanofilia. El Sur: 5.

SaID, Edward. 2008 [1997]. Orientalismo. Barcelona: De Bolsillo.

SCHMidT-Wielle, Friedhelm. 2012. Regionalismo abstracto y representación simbólica de la nación en la literatura latinoamericana de la región. Relaciones 130: 115-127.

Schütz, Günther. 1976. Correspondencia de Rufino José Cuervo con Rodolfo Lenz. Epistolario de Rufino José Cuervo con filólogos de Alemania, Austria y Suiza, vol. I, pp. 499-559. Bogotá: Instituto Caro y Cuervo.

Silva Castro, Raúl. 1961. Panorama literario de Chile. Santiago: Universitaria.

Silva Vildósola, Carlos. 1920. Prólogo, pp. i-iii. Zurzulita. Mariano Latorre. Santiago: Editorial Chilena.

Subercaseaux, Benjamín. 1943. Prólogo. Zurzulita. Mariano Latorre. 2a ed. Santiago: Nascimento.

Subercaseaux, Bernardo. 2007. Historia de las Ideas y de la Cultura en Chile, tomo IV. Nacionalismo y cultura. Santiago: Universitaria.

2010. Historia del libro en Chile. Desde la Colonia hasta el Bicentenario. $3^{\text {a }}$ ed. Santiago: Lom Ediciones.

1997. Identidad de género y nación. Prismas 1: 45-51.

2018. De la imprenta a la industria editorial. Historia crítica de la literatura chilena. Vol. II. La era republicana. Independencia y formación del estado nacional, 
pp. 359-373. Bernardo Subercaseaux (coord.). Grínor Rojo y Carlos Arcos (eds.) Santiago: Lom Ediciones.

Tijera. 20 noviembre 1913. Salpicón. Sucesos 585: 19.

VicuÑa, MANUEL. 2001. La belle époque chilena: alta sociedad y mujeres de élite en el cambio de siglo. Santiago: Universitaria.

ZoLA, ÉmiLE. s/f [1877]. L'assommoir (La taberna). $3^{\mathrm{a}}$ ed. Trad. Amancio Peratoner. Barcelona: Maucci. 